\title{
Allocentric versus Egocentric Representation of Remembered Reach Targets in Human Cortex
}

\author{
Ying Chen, ${ }^{1,2,3}$ Simona Monaco, ${ }^{1,3}$ Patrick Byrne, ${ }^{1}$ Xiaogang Yan, ${ }^{1,3}$ Denise Y.P. Henriques, ${ }^{1,2}$ \\ and J. Douglas Crawford ${ }^{1,2,3}$ \\ ${ }^{1}$ Center for Vision Research and 2Departments of Psychology, Biology, and Kinesiology and Health Science, York University, Toronto, Ontario M3J 1P3, \\ Canada, and ${ }^{3}$ Canadian Action and Perception Network, York University, Toronto, Ontario M3J 1P3, Canada
}

\begin{abstract}
The location of a remembered reach target can be encoded in egocentric and/or allocentric reference frames. Cortical mechanisms for egocentric reach are relatively well described, but the corresponding allocentric representations are essentially unknown. Here, we used an event-related fMRI design to distinguish human brain areas involved in these two types of representation. Our paradigm consisted of three tasks with identical stimulus display but different instructions: egocentric reach (remember absolute target location), allocentric reach (remember target location relative to a visual landmark), and a nonspatial control, color report (report color of target). During the delay phase (when only target location was specified), the egocentric and allocentric tasks elicited widely overlapping regions of cortical activity (relative to the control), but with higher activation in parietofrontal cortex for egocentric task and higher activation in early visual cortex for allocentric tasks. In addition, egocentric directional selectivity (target relative to gaze) was observed in the superior occipital gyrus and the inferior occipital gyrus, whereas allocentric directional selectivity (target relative to a visual landmark) was observed in the inferior temporal gyrus and inferior occipital gyrus. During the response phase (after movement direction had been specified either by reappearance of the visual landmark or a pro-/anti-reach instruction), the parietofrontal network resumed egocentric directional selectivity, showing higher activation for contralateral than ipsilateral reaches. These results show that allocentric and egocentric reach mechanisms use partially overlapping but different cortical substrates and that directional specification is different for target memory versus reach response.
\end{abstract}

Key words: allocentric reach; directional selectivity; egocentric reach; fMRI

\section{Introduction}

To reach for a remembered object, one must maintain an internal spatial representation of its location, either relative to some egocentric (body-fixed) frame of reference, such as the eyes, head, or shoulder, or some allocentric (world-fixed) frame of reference, such as a stable visual landmark (Bridgeman et al., 1997; Burnod et al., 1999; Carrozzo et al., 2002; Olson, 2003; Crawford et al., 2011). Behavioral studies have investigated the influence of visual landmarks on reach (Krigolson and Heath, 2004; Obhi and Goodale, 2005; Krigolson et al., 2007) and the interactions between egocentric and allocentric representations for memoryguided targets (Byrne and Crawford, 2010; Byrne et al., 2010; Chen et al., 2011; Schütz et al., 2013). However, the cortical mechanisms for egocentric reach are still debated, and the neural mechanisms for allocentric reach are essentially unknown.

Received April 9, 2014; revised July 24, 2014; accepted Aug. 7, 2014.

Author contributions: Y.C., S.M., P.B., X.Y., D.Y.P.H., and J.D.C. designed research; Y.C. performed research; Y.C., S.M., P.B., and J.D.C. analyzed data; Y.C., S.M., and J.D.C. wrote the paper.

This work was supported by the Canadian Institute of Health Research. J.D.C. was supported by a Canada Research Chair award. Y.C. was supported by an Ontario Graduate Scholarship. S.M. was supported by the CAN-ACT NSERC CREATE program. We thankS. Sun for computer programming support.

The authors declare no competing financial interests.

Correspondence should be addressed to Dr. Ying Chen, Centre for Vision Research, Room 0009A LAS, Keele Street, Toronto, Ontario M3J 1P3, Canada. E-mail: liuc@yorku.ca.

DOI:10.1523/JNEUROSCI.1445-14.2014

Copyright $\odot 2014$ the authors $\quad 0270-6474 / 14 / 3412515-12 \$ 15.00 / 0$
Neuropsychological studies of vision and action suggest that egocentric coding is associated with parietal cortex (which is closely associated with frontal cortex), and allocentric coding is associated with temporal cortex (Goodale and Haffenden, 1998; Milner and Goodale, 2006; Schenk, 2006; Milner and Goodale, 2008). Primate neurophysiological studies and human fMRI studies have investigated the neural substrates of egocentric reaching/pointing in considerable detail (Andersen et al., 1993, 1998; Batista et al., 1999; Connolly et al., 2000, 2003; DeSouza et al., 2000; Andersen and Buneo, 2002; Astafiev et al., 2003; Medendorp et al., 2003, 2005a; Prado et al., 2005; Fernandez-Ruiz et al., 2007; Beurze et al., 2010). These studies have shown that posterior parietal cortex (PPC) and dorsal premotor cortex (PMd) are involved in egocentric representation of reach targets, with a contralateral left-right topography in human cortical areas, such as midposterior intraparietal sulcus (mIPS), and superior parieto-occipital cortex (SPOC) (Vesia and Crawford, 2012). In comparison, allocentric mechanisms have only been studied for spatial judgments in cognitive tasks (Fink et al., 2000; Galati et al., 2000; Committeri et al., 2004; Neggers et al., 2006; Zaehle et al., 2007), saccade coding (Olson and Gettner, 1995; Olson and Tremblay, 2000; Sabes et al., 2002; Olson, 2003), and manual distance judgments (Thaler and Goodale, 2011). To our knowledge, the neural substrates for allocentric coding of reach targets (i.e., target direction relative to a visual landmark: allocentric 
directional selectivity) have never been studied or directly compared with egocentric mechanisms (i.e., target direction in an egocentric frame: egocentric directional selectivity).

Here, we used an event-related fMRI paradigm: (1) to explore brain regions involved in spatial coding of remembered reach targets in egocentric and allocentric frames of reference; (2) to establish which brain areas show directional selectivity when encoding target location in egocentric versus allocentric coordinates; and (3) to compare this to egocentric directional selectivity during the response phase. The results showed that, although allocentric and egocentric mechanisms for reach target coding show considerable overlap, they differ in key areas, both from each other and from the cortical activity during the reach response.

\section{Materials and Methods}

Participants. Thirteen right-handed participants ( 9 females and 4 males, 23-40 years of age) took part in this study and gave informed consent. All had normal or corrected to normal vision and had no known neuromuscular deficits. This study was approved by the York Human Participants Review Subcommittee.

Experimental stimuli and apparatus. Visual stimuli consisted of dots of light produced by fiber optic cables that were embedded in a custom-built board mounted atop a platform. The platform was placed above the abdomen of the participant and affixed to the scanner bed through notches. The height and tilt of the platform could be adjusted to allow participants to reach comfortably to the stimuli (Fig. $1 A)$. A computer-controlled touch screen (Keytec, dimensions $170(\mathrm{~h}) \times 128(\mathrm{v}) \mathrm{mm})$ was attached on the custom-built board to allow the recording of reaching endpoints. An eye-tracking system (iView $\mathrm{X}$ ) was used in conjunction with the MRI-compatible Avotec Silent Vision system (RE-5701) to record gaze movements from the right eye during fMRI experiments.

The head of the participant was slightly tilted ( $\sim 20$ degrees) to allow direct viewing of the stimuli without using mirrors. The board was approximately perpendicular to the direction of gaze on the central fixation point and was placed $\sim 60 \mathrm{~cm}$ away from the eyes of the participants. The upper arm was strapped to the bed to avoid artifacts due to the motion of the shoulder and the head; therefore, reaching consisted of movements of the forearm and hand. A button pad was placed on the left side of the participant's abdomen. The button pad was used as a response key for the Color report task as well as the starting position for the right hand for the egocentric reach and allocentric reach tasks (see Experimental paradigm and timing). Participants wore headphones to hear audio instructions about the upcoming trial. During the experiment, participants were in complete darkness with the only exception of dots of light that served as visual stimuli. The dots of light were bright enough to be seen by the participant but too dim to allow viewing of the workspace. The hand was never visible to subjects, even during reaching.

Each dot of light had a diameter of $3 \mathrm{~mm}$, and different colors were associated with different stimuli: yellow for the fixation dot, green or red for the target to be reached, blue for the visual landmark, and white for the mask. There were seven possible fixation points horizontally separated from each other by one degree, with the central one aligned to the participant's body midline. The dots of light corresponding to targets and relative visual landmarks were located to the left and the right of the fixation point. They were also separated from each other by a visual angle of one degree. There were four dots on the left and four dots on the right of the fixation point. Because these dots could be red, green, or blue, they could be used as a target or a visual landmark in different trials. This allowed us to have 40 different combinations of target and visual landmark locations, in which the target could be located one or two visual degrees to the left or to the right of a visual landmark. Initial target and visual landmark were both presented either to the left or to the right of the fixation point. Therefore, the target could be displayed from one to nine visual degrees to the left or to the right of the initial fixation. The target presented to the right or left of the gaze was also to the right or left 
of body midline (for instance: target right of gaze $=$ target right of body midline, target left of gaze $=$ target left of body midline).

The mask consisted of 20 dots of light organized in two rows: one above and one below the targets. The location of each dot for the mask was aligned with the midpoint between dots serving as targets and visual landmarks. The purpose of having a mask was to avoid potential aftereffects created by the illumination of the target and the landmark in the dark. Because our analyses focused mainly on the delay phase, it was critical that participants were using memory information to recruit the location of the target rather than exploiting the afterimage of the target for the upcoming reach.

Experimental paradigm and timing. We used an event-related design to investigate three main questions. First, we examined the cortical circuits involved in processing the location of a reach target in egocentric and allocentric coordinates during the memory delay. Second, we investigated the areas showing directional selectivity when encoding target location in an egocentric versus an allocentric representation during the memory delay. Third, we examined the brain areas involved in processing the reach direction for action planning and execution.

The paradigm included three tasks: egocentric reach (Ego), allocentric reach (Allo), and color report (Color) (Fig. 1B). In the allocentric reach task, participants had to remember and later reach toward the location of the target relative to a visual landmark. The target and the landmark were initially presented together; then the landmark reappeared at the same or at a different location (Fig. 1B; for details, see below). Because the landmark could reappear to the left or right of the midline, the horizontal position of the reach could not be predicted during the initial memory period (the delay phase). In the egocentric reach task, participants had to remember and reach toward the remembered location of the target, either at the location it initially appeared (pro-reach) or toward its mirror location in the opposite hemi-field (anti-reach). The anti-reach condition was included to equalize the motor aspects of the Ego and Allo tasks (i.e., in both cases the horizontal reach position could only be computed when the instruction to perform a reach or an anti-reach was given). Therefore, in both tasks, the activation elicited during the delay phase could only be related to the encoding horizontal target location, rather than reach planning (although other types of directionally nonspecific motor preparation for a forward reach might occur during this phase). The color report task served as a control, and participants had to press a button one or two times depending on whether the target was green or red.

Before each trial, a recorded voice instructed the participant about the upcoming task: "Reach to target" (in egocentric reach tasks), "Reach relative to cue" (in allocentric reach tasks), "Report target color" (in color report tasks). Although the audio cue occurred $8 \mathrm{~s}$ before presentation of the target, participants performed the actual movement upon the go instruction only at the end of the same trial.

Each trial started with the presentation of a fixation point that participants were required to fixate throughout the experiment. After $2 \mathrm{~s}$, a target was presented for $2 \mathrm{~s}$ along with a landmark. Depending on the initial instruction, after the target and landmark disappeared, participants had to remember the location of the target regardless of the landmark (egocentric reach), the location of the target relative to the landmark (allocentric reach), or the color of the target (color report). After the brief presentation of target and landmark, the fixation point shifted to the center and was followed by a $12 \mathrm{~s}$ delay during which a mask appeared. By shifting the fixation point before the delay period, the possibility of using the fixation point as an allocentric cue in the Ego task was removed. To keep all tasks as similar as possible, the fixation shift was retained in the Allo and Color tasks as well. After the delay, the landmark reappeared for $2 \mathrm{~s}$ either at its original location or at another location in the same or opposite hemifield relative to its first appearance. Subsequently, an auditory signal cued the participant to reach toward the instructed egocentric target location (audio: “Target”), the location opposite to the egocentric target location (audio: "Opposite"), or the allocentric target location (audio: "Reach"). In the color report task, participants were informed to press the button corresponding to the color of the previously presented target (audio: "Color"). Our paradigm consisted of five phases (fixation point, stimulus presentation, delay, landmark presentation, response) (Fig. 1B). A gap of $16 \mathrm{~s}$ was inserted between each trial to allow the hemodynamic response to return to baseline. Each run consisted of 18 trials, and each task was repeated six times in a random order yielding a run time of $\sim 12 \mathrm{~min}$. Each participant performed six runs. Our design consisted of three factors: 3 tasks (Ego, Allo, Color) $\times 2$ Target relative to gaze (Left of Gaze: LG and Right of Gaze: RG) $\times 2$ Target relative to landmark (Left of Landmark: LL and Right of Landmark: RL). This design gave rise to 12 conditions in total: Ego: LG:LL, Ego: LG:RL, Ego: RG:LL, Ego: RG:RL, Allo: LG:LL, Allo: LG:RL, Allo: RG:LL, Allo: RG:RL, Color: LG:LL, Color: LG:RL, Color: RG:LL, Color: RG:RL. The 12 conditions were counterbalanced in each run. The "Left of Gaze" and "Right of Gaze" conditions included targets located to the left or right of the fixation point regardless of their distance from it. Similarly, the "Left of Landmark" and "Right of Landmark" conditions included targets located to the left or right of a visual landmark regardless of their distance from it (i.e., we did not include a target distance-from center covariate in our GLM). For the purpose of the analyses, we collapsed target locations into "Left" and "Right" relative to either gaze or visual landmark. Participants were trained to perform the tasks one day before the scanning session.

Behavioral recordings. Following our fMRI experiments, we inspected eye and hand position data for every trial to ensure that subjects correctly followed all instructions. Errors in eye movements were defined as trials in which subjects made a saccade toward the target or the visual landmark or were not able to maintain fixation during the delay phase. Errors in reaching movements were defined as trials in which the location of the reaching endpoint and the actual reach target location were on opposite sides relative to the midline on the touch screen. Trials that showed errors in eye and/or reach movements were modeled as confound predictors and excluded from further fMRI analyses (see Data analyses). All participants completed at least 95 correct trials ( $88 \%$ of the total trials).

To confirm that subjects actually used egocentric or allocentric visual information in the Ego or Allo task to encode target location as instructed, and to exclude the possibility that they simply reached toward the correct side of the screen midline, we performed a correlation analysis. First, we calculated the absolute distance between a subject's reaching response for a given trial and the screen midline; then we calculated the distance between the proper target location (whether egocentriclly or allocentrically defined) and the screen midline. If subjects were attempting to reach to the correct location, as instructed, these two values should be well correlated in both the Ego and Allo tasks. The across-subject means of these correlation coefficients were $0.31 \pm 0.04$ for the Ego task and $0.45 \pm 0.04$ for the Allo task. We then applied Fisher's r-to- $z$ transformation to the individual subject correlation coefficients ( $r$ ) so that we could use standard $t$ tests to compare the between-subjects means of $z$ values to zero. If subjects were using the egocentric or allocentric spatial information for target coding, then these coefficients should have been significantly greater than zero. Standard $t$ tests showed that mean of correlation coefficient was significantly greater than zero in both tasks $\left(\mathrm{p}_{\text {ego }}=0.00001, \mathrm{p}_{\text {allo }}=0.000002\right)$. Thus, both target location and allocentric cue location influenced behavior.

To further quantify participants' performance, we calculated the absolute error and the variable error in the horizontal dimension for each participant and each reach task (Ego or Allo), respectively. The absolute error is the absolute value of the distance between the target position and the endpoint of a reach movement and represents the amount by which the target was missed. The variable error was computed by taking the SD of the constant reaching errors and represents the variability of reach endpoints around the average endpoint. The across-subject means of absolute error were $1.42 \pm 0.09 \mathrm{~cm}$ for the Ego task and $1.48 \pm 0.07 \mathrm{~cm}$ for the Allo task. The across-subject means of variable error were $1.65 \pm$ $0.08 \mathrm{~cm}$ for the Ego task and $1.63 \pm 0.05$ for the Allo task.

Imaging parameters. The experiment was conducted at the neuroimaging center of York University with a 3-T whole-body MRI system (Siemens Magnetom TIM Trio). The posterior half of a 12-channel head coil ( 6 channels) was placed at the back of the head in conjunction with a 4-channel flex coil over the anterior part of the head (Fig. 1A). The former was tilted at an angle of $20^{\circ}$ to allow a reach-to-touch movement to the touch screen as well as the direct viewing of the stimuli. 
Functional data were acquired using an EPI (echo-planar imaging) sequence (repetition time $[\mathrm{TR}]=2000 \mathrm{~ms}$; echo time $[\mathrm{TE}]=30 \mathrm{~ms}$; flip angle $[\mathrm{FA}]=90^{\circ}$; field of view $[\mathrm{FOV}]=192 \mathrm{~mm} \times 192 \mathrm{~mm}$, matrix size $=64 \times 64$ leading to in-slice resolution of $3 \mathrm{~mm} \times 3 \mathrm{~mm}$; slice thickness $=3.5 \mathrm{~mm}$, no gap; 35 transverse slices angled at $\sim 25^{\circ}$ covering the whole brain). The slices were collected in ascending and interleaved order. During each experimental session, a T1-weighted anatomical reference volume was acquired using a MPRAGE sequence $(\mathrm{TR}=1900 \mathrm{~ms}$; $\mathrm{TE}=2.52 \mathrm{~ms}$; inversion time $\mathrm{TI}=900 \mathrm{~ms} ; \mathrm{FA}=9^{\circ} ; \mathrm{FOV}=256 \mathrm{~mm} \times$ $256 \mathrm{~mm} \times 192 \mathrm{~mm}$, voxel size $=1 \times 1 \times 1 \mathrm{~mm}^{3}$ ).

Preprocessing. Data were analyzed using the Brain Voyager QX 2.2 software (Brain Innovation). The first 2 volumes of each fMRI scan were discarded to avoid T1 saturation effects. For each run, slice scan time correction (cubic spline), temporal filtering (to remove frequencies $<2$ cycles/run), and 3D motion correction (trilinear/sinc) were performed. The 3D motion correction was performed aligning each volume to the volume of the functional scan closest to the anatomical scan. After inspection of the $3 \mathrm{D}$ motion correction parameters, we discarded runs showing abrupt head motion exceeding $1 \mathrm{~mm}$ or $1^{\circ}$. The whole dataset of one participant was discarded from the analyses because of head motion exceeding our set threshold; therefore, data from 12 participants were included in the group GLM. The functional runs were coregistered to the anatomical image. Functional data were then transformed into standard Talairach space, using the spatial transformation parameters from each participant's anatomical image. Functional data were spatially smoothed using a FWHM of $8 \mathrm{~mm}$.

Data analyses. For each participant, we used a GLM that included 21 predictors in total. In particular, one predictor was used for the eye movement to the fixation point ( $2 \mathrm{~s}$ or 1 volume). In the stimulus presentation phase, we used one predictor for target-landmark presentation and gaze shift ( $4 \mathrm{~s}$ or 2 volumes). In the delay phase, we used 12 predictors (12 s or 6 volumes), one for each experimental condition (see "Experimental paradigm and timing"). In the landmark presentation phase, we used one predictor ( $2 \mathrm{~s}$ or 1 volume). In the response phase ( $4 \mathrm{~s}$ or 2 volumes), we considered two factors: 3 tasks (Ego, Allo, color) $\times 2$ target relative to gaze (Left of Gaze: LG and Right of Gaze: RG), which gave rise to six predictors: Ego reach: LG, Ego reach: RG, Allo reach: LG, Allo reach: RG, color: LG, color: RG. This allowed us to explore the brain areas involved in processing the direction of the movement during reach response. Each predictor was derived from a rectangular wave function convolved with a standard hemodynamic response function (Brain Voyager QX's default double-gamma hemodynamic response function). In addition, we added six motion correction parameters and errors made in eye and reach data as confound predictors.

Voxelwise analyses. We performed contrasts on $\beta$ weights $(\beta)$ using an RFX (group random effects) GLM where percentage signal change transformation had been performed. Our questions were aimed at exploring brain areas that encode the target location during the delay phase before the movement (for predictions, see Fig. 2). First, we expected that areas involved in coding of target location and/or motor preparation for reach during the delay phase would show higher activity in the egocentric and allocentric reach tasks as opposed to the color report task. This was tested with Contrast no. 1: [(Delay Ego + Delay Allo $)>$ Delay Color $]$, in which we collapsed the left and right locations of target relative to gaze and landmark in the delay phase. Second, we hypothesized that areas involved in egocentric coding of target location would show higher activation for the egocentric versus allocentric task. In contrast, areas involved in allocentric coding of target location would show higher activation for the allocentric versus egocentric task. Therefore, to further distinguish brain areas processing target location during the delay phase in egocentric versus allocentric coordinates, we performed Contrast no. 2: [Delay Ego $>$ Delay Allo]. Third, we expected that egocentric directional selectivity (target location relative to gaze) would be revealed by higher activation for targets located to the left or to the right relative to the gaze. To explore areas showing egocentric directional selectivity, we performed Contrast no. 3: [Delay Ego (Target Right of Gaze) > Delay Ego (Target Left of Gaze)], in which we collapsed left and right target locations relative to landmark. Fourth, we expected that allocentric directional selectivity (target location relative to landmark) would be revealed by higher activation for target location to the left or to the right of the landmark. To investigate brain areas involved in allocentric directional selectivity, we performed Contrast no. 4: [Delay Allo (Target Right of Landmark) > Delay Allo (Target Left of Landmark)], in which we collapsed left and right target locations relative to gaze. Finally, we tested whether areas in the parietofrontal network of each hemisphere are involved in processing the location of the target in the contralateral visual hemifield for reaching movements during the response phase. This was tested by Contrast no. 5 : [Reach (Target Right of Gaze) > Reach (Target Left of Gaze)] in egocentric and allocentric reach tasks, respectively. For this contrast, direction was defined according to the direction of the actual reach (i.e., reach direction relative to gaze).

Activation maps for group voxelwise results were overlaid either on the inflated anatomical image of one representative participant (see Figs. 3 and 8 ) or on the average anatomical image from 12 participants (see Figs. 4, 5, 6, and 7). To correct for multiple comparisons, we performed a cluster threshold correction (Forman et al., 1995) using BrainVoyager's cluster-level statistical threshold estimator plug-in. This algorithm uses Monte Carlo simulations (1000 iterations) to estimate the probability of a number of contiguous voxels being active purely due to chance while taking into consideration the average smoothness of the statistical maps. Areas that did not survive a cluster threshold correction were excluded from further analyses. The estimated minimum cluster size was 11 voxels $\left(3 \mathrm{~mm}^{3}\right.$ ) for a total volume of $297 \mathrm{~mm}^{3}$. Subsequently, a Bonferroni correction was applied to paired-sample $t$ tests on $\beta$ weights extracted from the areas that survived the cluster threshold correction. The Bonferroni correction was performed for three comparisons (corrected $p=$ 0.0167 ) aimed at answering our main questions. The first group of comparisons performed on the results of Contrast nos. 1 and 2 was aimed at exploring differences between brain areas involved in egocentric and allocentric target coding. Therefore, we performed the following comparisons: Ego versus Color Allo versus Color, Ego versus Allo. The second group of comparisons performed on the results of Contrast no. 3 was aimed at investigating whether the coding of left and right target location relative to gaze was specific to the egocentric task or whether it applied also to other tasks. Therefore, we performed the comparison $R G$ versus $L G$ in Ego, Allo, and Color tasks, respectively. The third group of comparisons performed on the results of Contrast no. 4 was aimed at assessing whether the coding of target location relative to the landmark was specific to the allocentric task or it applied also to other tasks; therefore, we performed the comparison $R L$ versus $L L$ in Ego, Allo, and Color tasks, respectively. The results on $\beta$ weights are plotted in bar graphs in Figures $3,4,5,6$, and 7 to illustrate significant differences between conditions at the corrected $p$ value, unless specified (see Results). Results that are nonindependent of the selection criteria are indicated in square brackets in the $\beta$ weight plots.

\section{Results}

The main purpose behind our experimental design was to compare cortical activity related to egocentric and allocentric reach coding during the delay phase, illustrated in Figure $1 B$. In this phase of our tasks, only target direction was specified (in egocentric or allocentric coordinates), whereas reach direction was specified only at the end of the landmark presentation phase through the reappearance of the landmark in the allocentric reach task, or the pro-/anti-reach instruction in the egocentric reach task. We will begin with a detailed analysis of the delay phase followed by a brief analysis of egocentric directional coding during the response phase.

\section{Task-related activation during the delay phase}

We used Contrast no. 1 [(Delay Ego + Delay Allo $)>$ Delay Color] to investigate the brain areas showing higher activation in the two experimental reach tasks (Ego, Allo) relative to the nonspatial control task (Color). The activation map for this contrast is shown on an inflated cortical surface and the $\beta$ weights are plotted in bar graphs (Fig. 3). The Talairach coordinates for the 
A Hypothesis 1:

Areas involved in reach target representation

(Contrast no. 1)

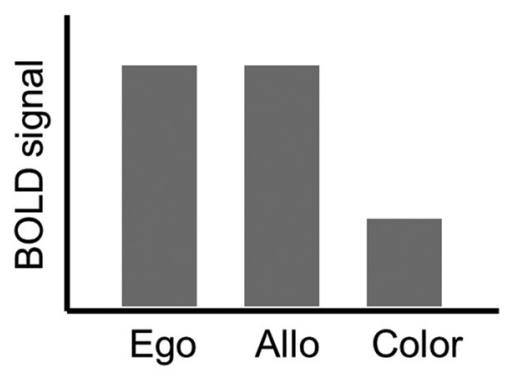

Hypothesis 2:
Areas coding reach target in allocentric coordinates (Contrast no. 2: Allo > Ego)
(Contrast no. 2: Ego > Allo)

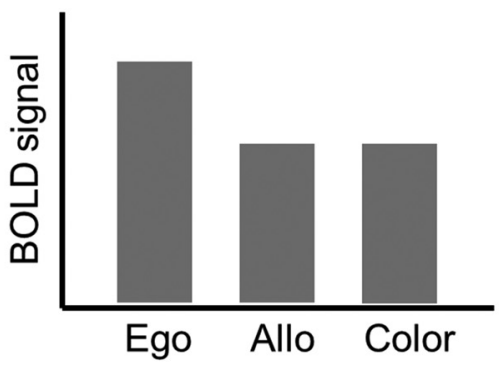

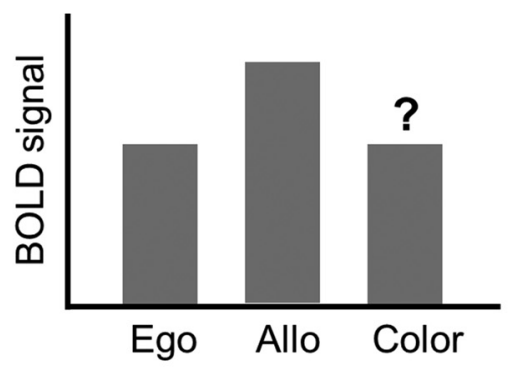

C

\section{Areas coding reach target relative to gaze (Egocentric directional selectivity)}

(Contrast no. 3)

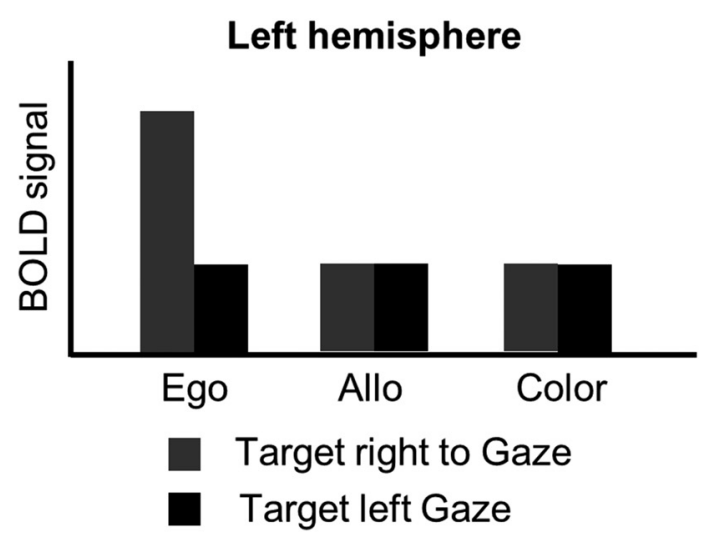

D

Hypothesis 4:

Areas coding reach target relative to landmark (Allocentric directional selectivity)

(Contrast no. 4)

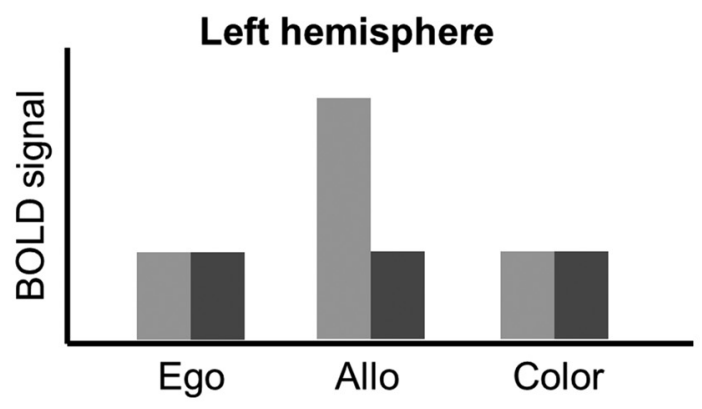

Target right to Landmark

Target left to Landmark

Figure 2. Predicted BOLD signal changes based on our four contrasts during the delay phase for the voxelwise group data. $A$, We expected that areas involved in reach target representation for Egocentric (Ego) and Allocentric (Allo) reach tasks would elicit higher activation compared with the Color report (Color) task. B, Areas involved in coding reach target in egocentric coordinates would elicit higher activation in the Ego task as opposed to the Allo task and vice versa. We did not have any specific prediction about the level of activation in the Color task compared with the Allo task for allocentric coding areas. $\boldsymbol{C}$, We expected that egocentric directional selectivity (target location relative to gaze) would be revealed by higher activation for target to the right versus left of the gaze in the left hemisphere. D, We expected that allocentric directional selectivity (target location relative to landmark location) would be revealed by higher activation for target to the right versus left of the landmark in the left hemisphere.

brain areas are shown in Table 1 . The activations shown by this contrast might be related to any aspect of target coding (not necessarily direction), cue location coding, and/or general motor preparation in anticipation of an oncoming reach movement.

This contrast revealed activation in PMd, mIPS, and SPOC bilaterally, middle frontal gyrus (MFG), inferior frontal gyrus (IFG), presupplementary motor area (PreSMA), and extrastriate cortex in the left hemisphere. Post hoc comparisons revealed higher activation for Ego versus Color in all these areas. In particular, this pattern was revealed in bilateral PMd ( $\mathrm{LH}: t_{(11)}=5.37, p=$ $\left.0.001 ; \mathrm{RH}: t_{(11)}=4.82, p=0.001\right), \operatorname{mIPS}\left(\mathrm{LH}: t_{(11)}=4.29, p=0.001\right.$; $\left.\mathrm{RH}: t_{(11)}=4.34, p=0.001\right)$, SPOC (LH: $t_{(11)}=5.93, p=0.001 ; \mathrm{RH}:$ $\left.t_{(11)}=5.30, p=0.001\right)$, left MFG $\left(t_{(11)}=2.94, p=0.013\right), \operatorname{IFG}\left(t_{(11)}\right.$ $=2.84, p=0.016)$, PreSMA $\left(t_{(11)}=2.96, p=0.013\right)$, and extra- striate cortex $\left(t_{(11)}=4.61, p=0.001\right)$. In addition, some of these areas also showed higher activation for Allo versus Color. In particular, we found this pattern in bilateral PMd $\left(\mathrm{LH}: t_{(11)}=4.23\right.$, $p=0.001$; RH: $\left.t_{(11)}=2.60, p=0.02\right)$, SPOC $\left(\mathrm{LH}: t_{(11)}=5.22\right.$, $\left.p=0.001 ; \mathrm{RH}: t_{(11)}=3.36, p=0.006\right)$, left MFG $\left(t_{(11)}=3.11, p=\right.$ $0.010), \operatorname{IFG}\left(t_{(11)}=3.20, p=0.008\right), \operatorname{PreSMA}\left(t_{(11)}=3.26, p=\right.$ $0.008), \operatorname{mIPS}\left(t_{(11)}=2.92, p=0.014\right)$, and extrastriate cortex $\left(t_{(11)}=3.11, p=0.010\right)$. Moreover, the post hoc $t$ tests also revealed higher activation for Ego than Allo in bilateral SPOC (LH: $t_{(11)}=3.68, p=0.004$; RH: $\left.t_{(11)}=3.64, p=0.004\right)$, right PMd $\left(t_{(11)}=3.47, p=0.005\right)$, and $\operatorname{mIPS}\left(t_{(11)}=2.63, p=0.02\right)$.

In summary, there was considerable overlap between areas showing higher activation in each of the two experimental reach tasks as opposed to the nonspatial control task. In par- 
ticular, these areas include bilateral PMd and SPOC, as well as left MFG, IFG, PreSMA, mIPS, and extrastriate cortex. Among these areas, bilateral SPOC, right PMd and mIPS also show higher activation for Ego versus Allo tasks.

To investigate possible additional areas showing higher activation for Ego versus Allo tasks and vice versa, we used Contrast no. 2, in which we directly compared Ego and Allo activation in the delay phase (Fig. 4). The Talairach coordinates for the brain areas found with this contrast are shown in Table 2. The results confirmed higher activation for Ego versus Allo tasks in bilateral SPOC, and PMd in the right hemisphere, and did not reveal any additional area with this pattern of activation. These "egocentric" areas also showed significantly higher activation in the allocentric task versus the color control task, suggesting that they were always active to some degree when a reach was being prepared.

Several other areas in the early visual cortex showed higher activation for the Allo versus Ego tasks (Fig. 5). In particular, we found bilateral lingual gyrus (LG) (LH: $t_{(11)}=4.04, p=0.002$; RH: $t_{(11)}=$ 3.75, $p=0.003$ ), calcarine sulcus (LH: $t_{(11)}=3.32, p=0.007$; RH: $t_{(11)}=3.38$, $p=0.006)$, and cuneus (LH: $t_{(11)}=3.78$, $p=0.003$; RH: $\left.t_{(11)}=3.71, p=0.003\right)$. In addition, these areas also showed higher activation for Color versus Ego, including bilateral LG (LH: $t_{(11)}=3.22, p=0.008$; RH: $\left.t_{(11)}=2.97, p=0.013\right)$, calcarine sulcus (LH: $t_{(11)}=3.21, p=0.008$; RH: $t_{(11)}$ $=3.78, p=0.003)$, and cuneus (LH: $t_{(11)}$ $=3.45, p=0.005$; RH: $t_{(11)}=3.57, p=$ $0.004)$ and no difference between Allo versus Color tasks. This might be because early visual cortex was not selective for spatial memory in our experiment (see Discussion).

In summary, these results demonstrate a parietofrontal network involved in spatial memory of target for reaching movements. In particular, we show the presence of allocentric target representation in early visual areas in addition to an overlapping parietofrontal circuit recruiting egocentric as well as allocentric target representation. In particular, whereas egocentric target coding preferentially relies on areas of the parietofrontal network, such as PMd, mIPS, and SPOC, allocentric target coding preferentially relies on early visual cortex, such as LG, calcarine, and cuneus. However, this coding was not discretely separate; in our task design, "egocentric" areas also showed activity in the allocentric task, and "allocentric" areas also showed activity in the Color task.

\section{LH PreSMA} confidence intervals.
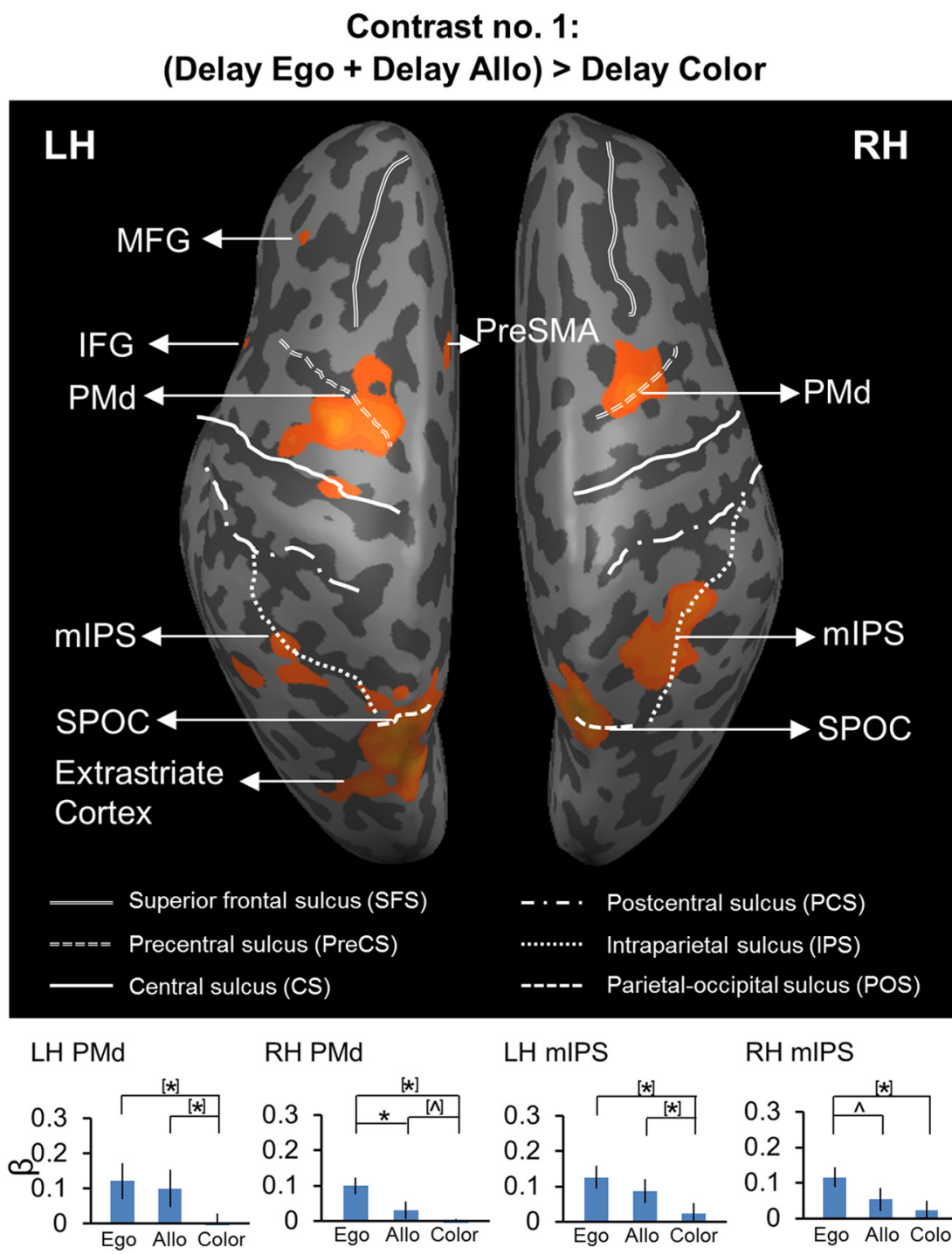

LH mIPS
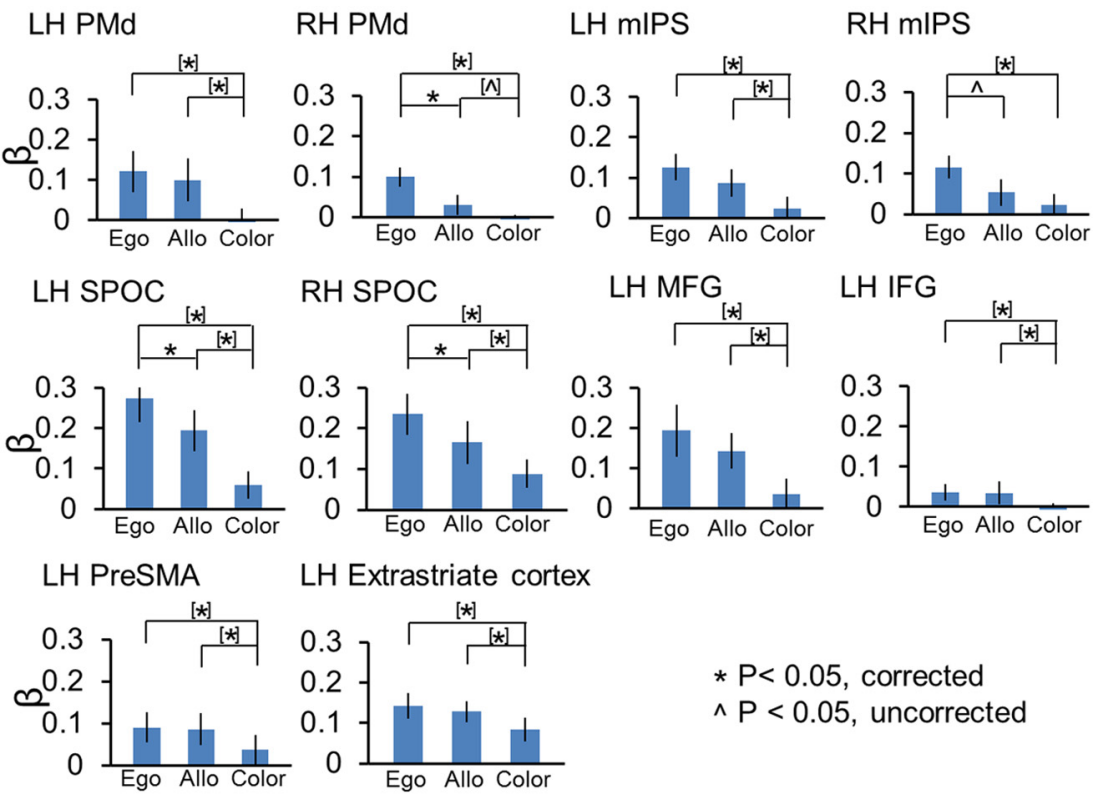

LH Extrastriate cortex

LH MFG
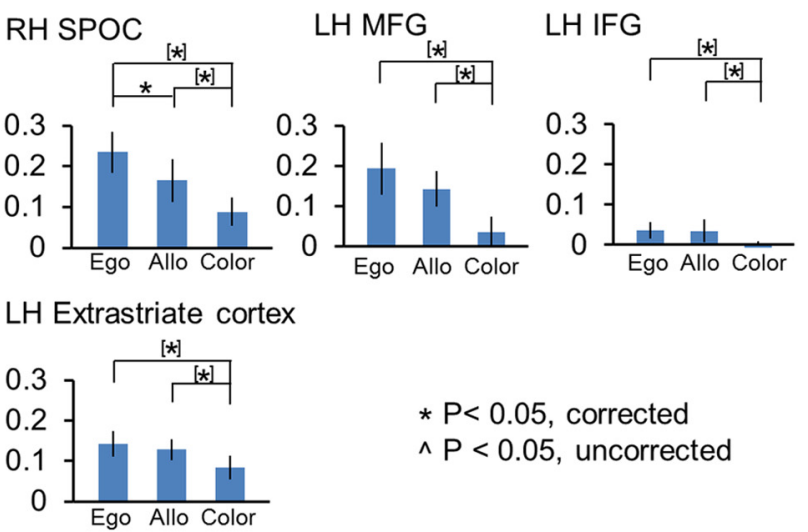

* $\mathrm{P}<0.05$, corrected

$\wedge \mathrm{P}<0.05$, uncorrected

Figure 3. Voxelwise statistical map obtained with the RFX GLM and activation levels for each area shown with the Contrast no. $1[$ (Delay Ego + Delay Allo) $>$ Delay Color]. Top, Activation map displayed on the inflated brain of one representative participant. Bottom, Bar graphs represent the $\beta$ weights for the three tasks in each area. *Significant difference for $p<0.05$. $\wedge$ Significant difference for $p<0.05$, uncorrected. [ ${ }^{*}$ ]Significant difference for $p<0.05$, non-independent of the criteria used to select the area. $[\wedge$ Significant difference for $p<0.05$ uncorrected, non-independent of the criteria used to select the area.Error bars indicate $95 \%$

Egocentric directional selectivity: target location relative to gaze

Next, we examined the directional selectivity revealed by cortical activation during the delay phase using Contrast no. 3 [Delay Ego 
Table 1. Talairach coordinates and number of voxels for contrast no. 1

\begin{tabular}{lrrrr}
\hline & \multicolumn{2}{l}{ Talairach coordinates } & \\
\cline { 2 - 3 } Brain areas & $x$ & $y$ & \multirow{2}{*}{$z$} & No. of voxels \\
\hline [(Delay Ego + Delay Allo) $>$ Delay Color $]$ & & & & \\
LH PMd & -29 & -4 & 50 & 992 \\
RH PMd & 25 & -6 & 50 & 943 \\
LH mIPS & -32 & -48 & 42 & 388 \\
RH mIPS & 31 & -48 & 42 & 917 \\
LH SPOC & -18 & -68 & 48 & 956 \\
RH SPOC & 19 & -65 & 48 & 867 \\
LH MFG & -41 & 32 & 34 & 426 \\
LH IFG & -41 & 13 & 10 & 693 \\
LH PreSMA & -4 & 12 & 48 & 496 \\
LH extrastriate cortex & -26 & -75 & 26 & 628 \\
\hline
\end{tabular}

\section{Contrast no. 2: $\quad$ Delay Ego > Delay Allo}
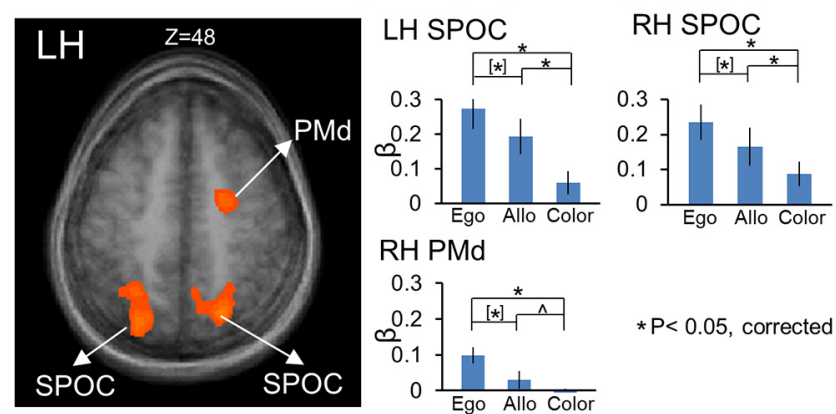

RH PMd

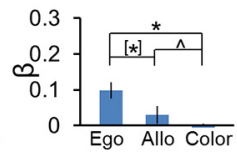

$* P<0.05$, corrected

Figure 4. Voxelwise statistical map obtained with the RFX GLM and activation levels for each area shown with the Contrast no. 2 [Delay Ego $>$ Delay Allo]. Left, Activation map overlaid on the averaged anatomical image from all 12 participants. Right, Bar graphs represent the $\beta$ weights for the three tasks in each area. Legends as in Figure 3.

Table 2. Talairach coordinates and number of voxels for contrast no. 2

\begin{tabular}{lrrrr}
\hline & \multicolumn{2}{l}{ Talairach coordinates } & \\
\cline { 2 - 3 } Brain areas & $x$ & $y$ & \multirow{2}{*}{ No. of voxels } \\
\hline Delay Ego $>$ Delay Allo & & & & \\
$\quad$ RH PMd & 25 & -6 & 50 & 943 \\
LH SPOC & -18 & -68 & 48 & 956 \\
RH SPOC & 19 & -65 & 48 & 867 \\
Delay Allo $>$ Delay Ego & & & & \\
LH LG & -6 & -58 & 3 & 592 \\
RH LG & 4 & -57 & 3 & 785 \\
LH calcarine & -2 & -79 & 3 & 736 \\
RH calcarine & 1 & -77 & 3 & 857 \\
LH cuneus & -2 & -87 & 20 & 869 \\
RH cuneus & 1 & -86 & 20 & 586 \\
\hline
\end{tabular}

(Target Right of Gaze) > Delay Ego (Target Left of Gaze)]. The Talairach coordinates of the brain areas are reported in Table 3. As shown in Figure 6, this contrast revealed higher activation for right versus left target location relative to the gaze in the left superior occipital gyrus (SOG) $\left(t_{(11)}=3.00, p=0.012\right)$ and inferior occipital gyrus IOG $\left(t_{(11)}=3.00, p=0.012\right)$. Neither area showed significant egocentric direction specificity in either the allocentric or color tasks, suggesting that the egocentric coding scheme in SOG and IOG was task-dependent. There was no active voxel showing higher activation for targets presented to the left compared with the right of the gaze in the egocentric reach task.

To investigate whether there were additional areas showing egocentric directional selectivity in the allocentric task, we ran the contrast [Delay Allo (Target Right of Gaze) > Delay Allo (Target

\section{Contrast no. 2: Delay Allo > Delay Ego}
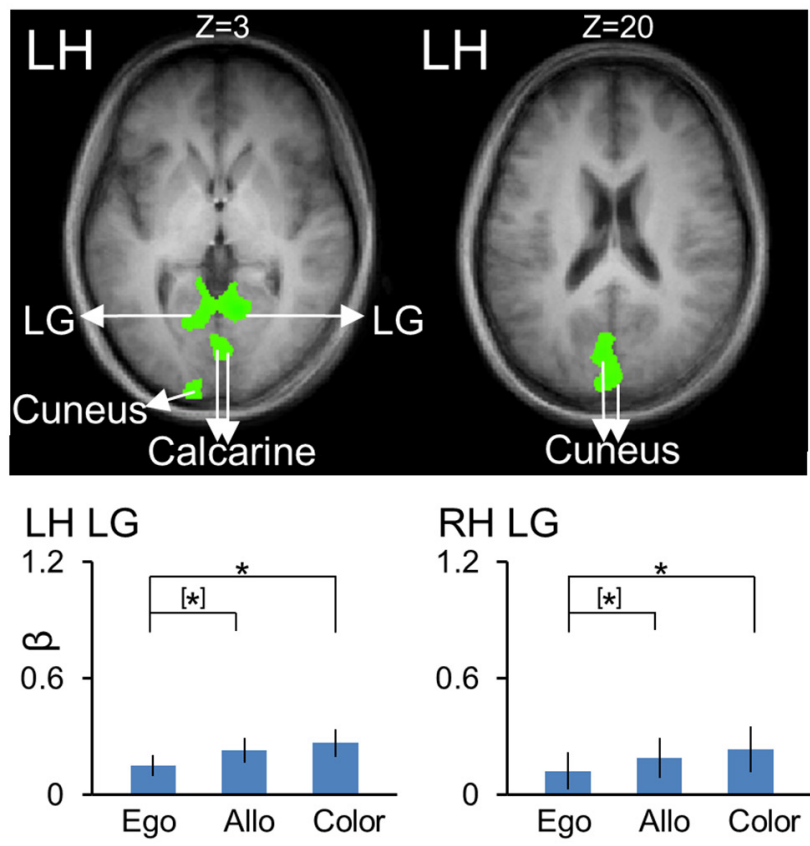

RH LG
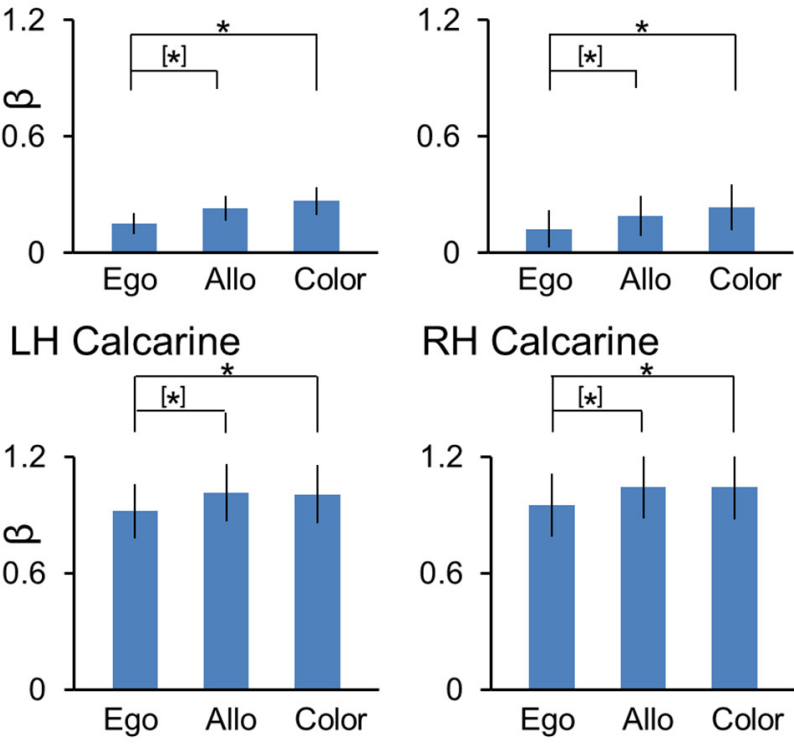

LH Cuneus

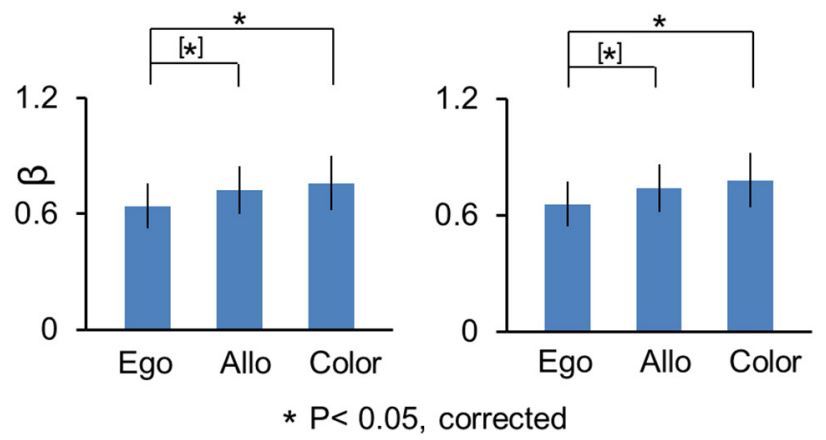

Figure 5. Voxelwise statistical map obtained with the RFX GLM and activation levels for each area shown with the Contrast no. 2 [Delay Allo $>$ Delay Ego]. Top, Activation map overlaid on the averaged anatomical image from all 12 participants. Bottom, Bar graphs represent the $\beta$ weights for the three tasks in each area. Legends as in Figure 3.

Left of Gaze)]. This analysis revealed an additional area (data not shown) in the right calcarine sulcus that showed higher activation for right versus left target location relative to gaze in Allo $t_{(11)}=$ $3.05, p=0.011)$. However, this area also showed egocentric directional specificity in color $\left(t_{(11)}=3.15, p=0.009\right)$, suggesting that the egocentric directional specificity observed in this area was not specific for reach tasks. 
Table 3. Talairach coordinates and number of voxels for contrast no. 3 and contrast no. 4

\begin{tabular}{lllrl}
\hline & \multicolumn{3}{l}{ Talairach coordinates } & \\
\cline { 2 - 3 } Brain areas & $x$ & $y$ & $z$ & No. of voxels \\
\hline $\begin{array}{l}\text { Delay Ego (Target Right of Gaze) }>\text { Delay Ego } \\
\quad \text { (Target Left of Gaze) }\end{array}$ & & & & \\
LH SOG & -12 & -95 & 4 & 380 \\
LH IOG & -16 & -86 & -11 & 422 \\
Delay Allo (Target Right of Landmark) > & & & & \\
$\quad$ Delay Allo (Target Left of Landmark) & -40 & -68 & 2 & 386 \\
LH IOG & & & & \\
Delay Allo (Target Left of Landmark) > Delay \\
Allo (Target Right of Landmark)
\end{tabular}

\section{Contrast no. 3: Delay Ego (Target Right of Gaze) > Delay Ego (Target Left of Gaze)}

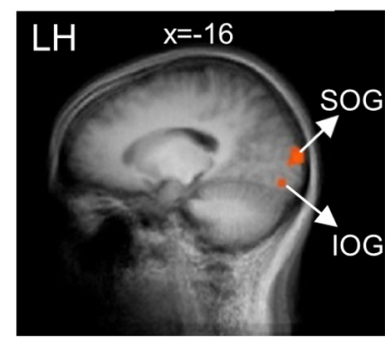

- Target Left of Gaze

- Target Right of Gaze

${ }^{*} \mathrm{P}<0.05$, corrected

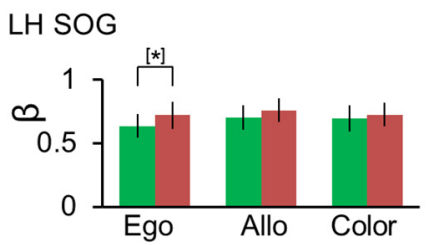

LH IOG

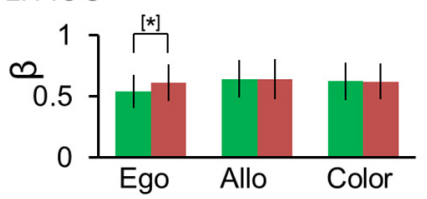

Figure 6. Voxelwise statistical map obtained with the RFX GLM and activation levels for each area shown with the Contrast no. 3, [Delay Ego (Target Right of Gaze) > Delay Ego (Target Left of Gaze)]. Left, Activation map overlaid on the averaged anatomical image from all 12 participants. Right, Bar graphs represent the $\beta$ weights for each condition in each area. Legends as in Figure 3.

Allocentric directional selectivity: target location relative to landmark

The key element to the design of this study was that it allowed us to analyze the neural coding of reach targets relative to visual landmarks in the allocentric reach task. To determine which brain regions were involved in allocentric directional selectivity of target location relative to the landmark, independent of other visual features, we performed Contrasts no. 4 [Delay Allo (Target Right of Landmark) > Delay Allo (Target Left of Landmark)]. The brain areas revealed by this contrast are shown in Figure 7. Talaraich coordinates are shown in Table 3.

As illustrated in Figure $7 A$, area IOG $\left(t_{(11)}=4.07, p=0.002\right)$ in the left hemisphere showed higher activation for target to the right versus left of the landmark. In addition, inferior temporal gyrus (ITG) in the left hemisphere $\left(\mathrm{LH}: t_{(11)}=3.13, p=0.009\right)$ showed higher activation for target to the left versus right of the landmark (Fig. 7B). These regions showed no significant allocentric coding during the egocentric reach and color report tasks, suggesting that these allocentric coding results are task specific.

To investigate whether there were additional areas showing allocentric directional selectivity in the egocentric task, we ran the contrast [Delay Ego (Target Right of Landmark) > Delay Ego (Target Left of Landmark)]. We found no significant active voxel for this contrast.

To summarize, we found significant allocentric directional selectivity in ITG and IOG. These results suggest that temporal and early visual cortices are specifically involved in the allocentric
Contrast no. 4:
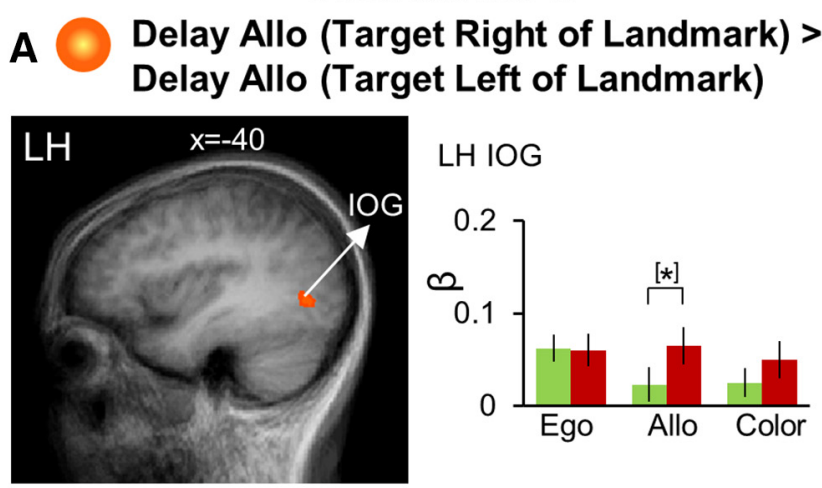

LH IOG

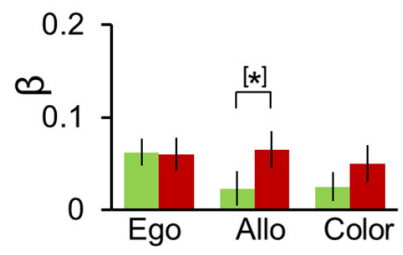

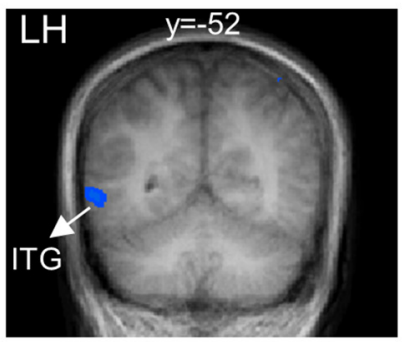

* $\mathrm{P}<0.05$, corrected

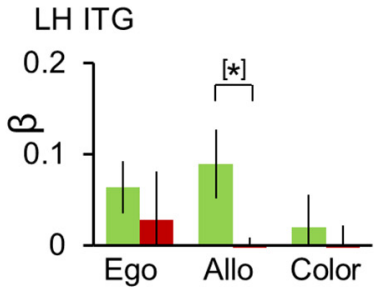

- Target Left of Landmark

- Target Right of Landmark

Figure 7. Voxelwise activation maps obtained with the RFX GLM and activation levels for each area shown with the Contrast no. $4(\boldsymbol{A})$ [Delay Allo (Target Right of Landmark) $>$ Delay Allo (Target Left of Landmark)] (B) [Delay Allo (Target Left of Landmark) > Delay Allo (Target Right of Landmark)]. Left panels, Activation maps overlaid on the averaged anatomical image from all 12 participants. Right panels, Bar graphs represent the $\beta$ weights for each condition in each area. Legends as in Figure 3.

coding of remembered target location in a task where allocentric landmark location is unpredictable.

Reach direction during movement response

As noted above, we did not observe egocentric directional selectivity in parietal or frontal cortex during the delay phase, unlike previous fMRI studies where reach direction could be planned during the delay phase (Medendorp et al., 2003, 2005b; Fernandez-Ruiz et al., 2007). This may have been because, in our delay phase, subjects could not yet plan the horizontal position of the actual reach. To test whether this was the case, we performed Contrast no. 5 [Reach (Target Right of Gaze) $>$ Reach (Target Left of Gaze)] during the response phase, that is, after reach direction was cued by either the reappearance of the landmark (Allo task) or the pro/anti instruction (Ego task). The hand was not visible to subjects during reach; therefore, these responses were not contaminated by visual feedback. The brain areas revealed by these contrasts are shown in Figure 8, and the Talairach coordinates are shown in Table 4.

This analysis revealed contralateral egocentric directional selectivity, primarily in the left hemisphere, including several parietofrontal areas that did not show directional selectivity during the delay phase. As shown in Figure 8, there was higher activation for reaching movements to the right versus left of gaze in the Ego task in left PMd, SMA, M1, S1, superior parietal lobe (SPL), extrastriate cortex and lateral occipital complex (LOC). In addi- 


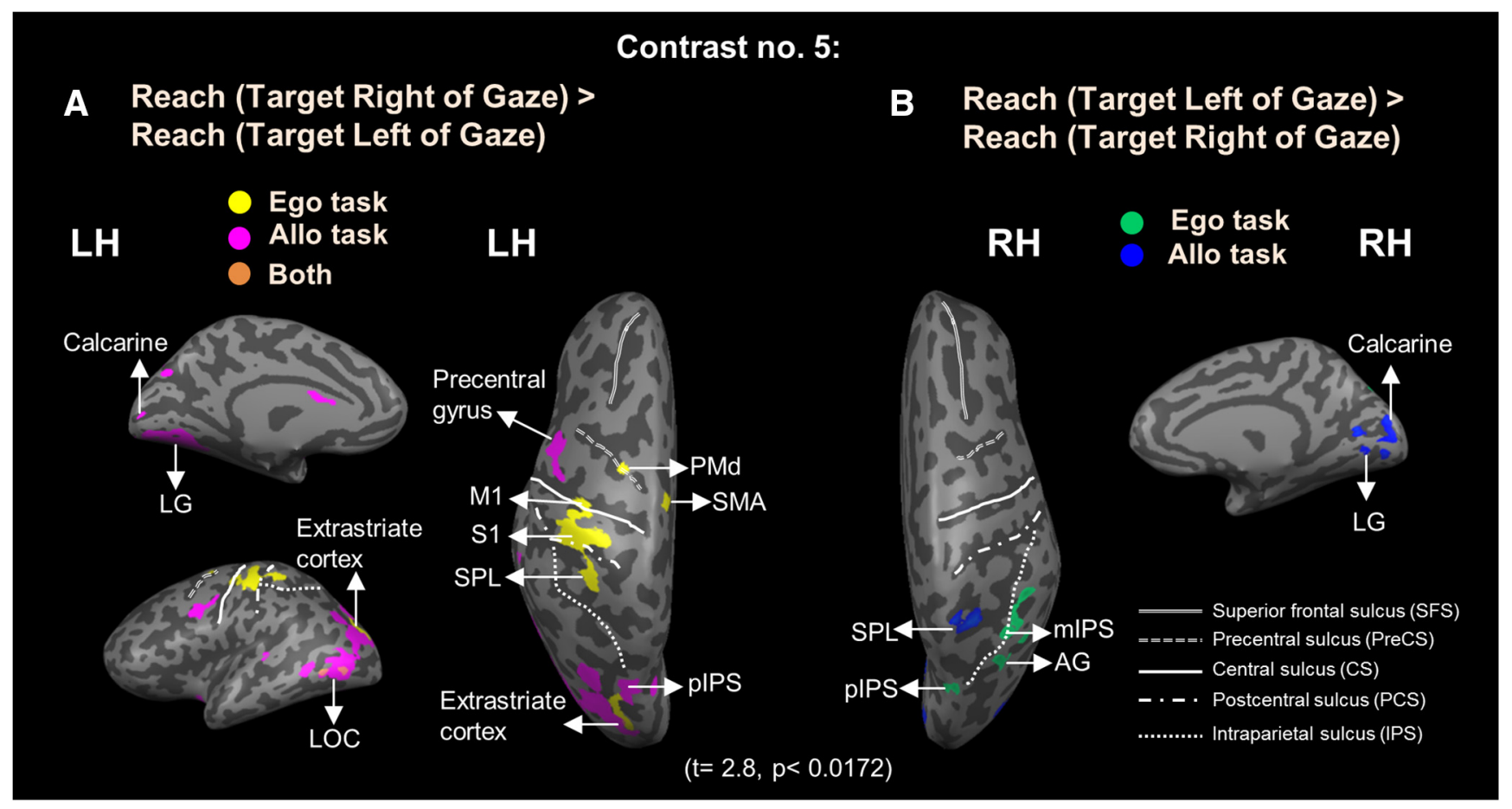

Figure 8. Voxelwise activation maps (RFX GLM) displayed on the inflated brain of one representative participant by using Contrast no. 5 ( $\boldsymbol{A}$ ) Reach (Target Right of Gaze) $>$ Reach (Target Left of Gaze). Yellow represents voxels activated in Ego task. Pink represents voxels activated in Allo task. Orange represents voxels activated in both tasks. $\boldsymbol{B}$, Reach (Target Left of Gaze) $>$ Reach (Target Right of Gaze). Green represents voxels activated in Ego task. Blue represents voxels activated in Allo task.

Table 4. Talairach coordinates and number of voxels for contrast no. 5

\begin{tabular}{|c|c|c|c|c|}
\hline \multirow[b]{2}{*}{ Brain areas } & \multicolumn{3}{|c|}{ Talairach coordinates } & \multirow[b]{2}{*}{ No. of voxels } \\
\hline & $x$ & $y$ & $z$ & \\
\hline \multicolumn{5}{|c|}{$\begin{array}{l}\text { Reach (Target Right of Gaze) }>\text { Reach } \\
\text { (Target Left of Gaze) }\end{array}$} \\
\hline \multicolumn{5}{|l|}{ Ego task: } \\
\hline LHPMd & -22 & -6 & 56 & 158 \\
\hline LHSMA & -4 & -10 & 55 & 362 \\
\hline LH M1 & -33 & -18 & 47 & 249 \\
\hline LHS1 & -38 & -24 & 53 & 352 \\
\hline LHSPL & -39 & -40 & 58 & 320 \\
\hline \multicolumn{5}{|l|}{ Allo task: } \\
\hline LH precentral gyrus & -49 & -2 & 41 & 358 \\
\hline LH pIPS & -23 & -68 & 32 & 318 \\
\hline LH calcarine & -7 & -86 & 7 & 164 \\
\hline LHLG & -9 & -76 & 3 & 234 \\
\hline \multicolumn{5}{|l|}{ Both tasks: } \\
\hline LH extrastriate cortex & -21 & -86 & 25 & 334 \\
\hline LHLOC & -45 & -74 & 6 & 412 \\
\hline \multicolumn{5}{|c|}{$\begin{array}{c}\text { Reach (Target Left of Gaze) }>\text { Reach } \\
\text { (Target Right of Gaze) }\end{array}$} \\
\hline \multicolumn{5}{|c|}{ Ego task: } \\
\hline RH mIPS & 40 & -54 & 41 & 244 \\
\hline RH AG & 35 & -68 & 41 & 374 \\
\hline RH pIPS & 30 & -73 & 41 & 386 \\
\hline \multicolumn{5}{|l|}{ Allo task: } \\
\hline RHSPL & 27 & -53 & 55 & 383 \\
\hline RH calcarine & 11 & -86 & 9 & 313 \\
\hline RH LG & 7 & -72 & 3 & 457 \\
\hline
\end{tabular}

tion, precentral gyrus, posterior intraparietal sulcus (pIPS), extrastriate cortex, LOC, calcarine, and LG showed higher activation for movements to the right as opposed to the left of gaze in the Allo task. Only three regions in the right hemisphere showed directional selectivity (this time preferring movements left vs right of gaze) in the Ego and Allo tasks, respectively. Spe- cifically, this pattern was revealed in mIPS, angular gyrus (AG), and pIPS for the Ego task, while in SPL, calcarine and LG for the Allo task.

In summary, during the response phase, we found egocentric directional selectivity in occipital, parietal, and frontal cortex, with structures in both hemispheres showing a directional preference for reaches made to the contralateral side relative to gaze.

\section{Discussion}

In this study, we used an experimental design that distinguished between egocentric versus allocentric coding of a reach target during the delay phase, and temporally separated target location memory from motor planning by only cuing reach direction at the start of the response phase. This distinguishes our experiment both from imaging studies that tested allocentric memory through some type of spatial judgment and from reach tasks where movement direction was cued from the beginning of each trial. Further, our analysis discriminated between (1) cortical areas that were active during egocentric and allocentric target coding, (2) areas that were differentially active for egocentric versus allocentric target coding, and (3) areas that were spatially selective in either egocentric or allocentric coordinates. This analysis revealed widespread, partially overlapping, patterns of cortical activation in the delay phase with, most importantly, divergent occipital-temporal mechanisms for allocentric versus egocentric target direction coding. Additional parietofrontal mechanisms for reach direction coding emerged during the response phase. We will consider each of these findings in detail.

Egocentric versus allocentric activation during the delay phase

Numerous human imaging studies have implicated superior occipital-partietal-frontal cortex in reach and pointing planning (Astafiev et al., 2003; Connolly et al., 2003; Medendorp et al., 
2003, 2005a; b; Brown et al., 2004, 2006; Prado et al., 2005; Fernandez-Ruiz et al., 2007; Beurze et al., 2009; Cavina-Pratesi et al., 2010; Fabbri et al., 2012; Konen et al., 2013). Our study generally agrees with their findings but places a stronger emphasis on target coding during our delay phase.

Our delay phase analysis revealed considerable overlap in extrastriate, parietal, and frontal areas involved in both allocentric and egocentric coding of reach targets compared with the nonspatial control task (color). However, bilateral SPOC and right PMd showed a preference for egocentric reach target coding, whereas early visual cortex (LG, calcarine, and cuneus) showed a preference for allocentric reach target coding. This allocentric preference in early visual cortex might be because this type of task requires subjects to remember multiple visual stimuli, whereas subjects only have to remember one visual stimulus in an egocentric task. Further, early visual cortex also showed higher activation in the color compared with the ego task, so it was not selective for spatial memory in our experiment. These results are consistent with imaging studies that have implicated occipital cortex in both spatial and feature-specific memory (Greenlee et al., 2000; Merriam et al., 2007; Harrison and Tong, 2009).

Unlike previous neuroimaging studies of allocentric coding that involved perceptual judgments (Galati et al., 2000; Committeri et al., 2004; Neggers et al., 2006; Zaehle et al., 2007) or manual judgments (Thaler and Goodale, 2011), we did not find higher allocentric activation in LOC or posterior parietal cortex (PPC) in our delay phase. This might be because our behavioral task separated the storage of target information during this phase from the response, whereas these processes were integrated in previous paradigms. Comparing across these studies suggests that the neural mechanisms used for allocentric coding are task-dependent.

\section{Directional coding during the delay phase}

Previous imaging studies demonstrated a preference for contralateral reach coding in gaze-centered coordinates in PPC (Medendorp et al., 2003, 2005; Fernandez-Ruiz et al., 2007). Previous imaging studies of allocentric judgments did not specifically test for allocentric directional selectivity (i.e., target location relative to cue) (Fink et al., 2000; Galati et al., 2000; Committeri et al., 2004; Neggers et al., 2006; Zaehle et al., 2007; Thaler and Goodale, 2011). However, neurophysiological studies have shown that saccade-related responses in parietofrontal neurons can code relative locations within an object (Olson and Gettner, 1995; Olson and Tremblay, 2000; Sabes et al., 2002; Olson, 2003). This analysis has not been done in a reach task.

Here, during the delay phase, we found a preference for contralateral reach targets (relative to gaze/midline) in left IOG and SOG during the egocentric task, whereas IOG and ITG coded target direction relative to a visual landmark in the allocentric task. These responses may represent the cumulative population activity of neurons with directional modulations similar to those reported in the previous oculomotor studies (e.g., Olson, 2003). The involvement of IOG in both egocentric and allocentric directional selectivity may indicate that these structures form a common hub for different types of visuospatial memory, whereas the differentiation of SOG for egocentric memory versus ITG for allocentric memory is consistent with previous theories of functional specialization within the dorsal and ventral visual streams (Milner and Goodale, 1995; Schenk, 2006). Again, these findings suggest a degree of task specificity not evident in previous perceptual studies (Merriam et al., 2007; Harrison and Tong, 2009).

As in a previous study (Committeri et al., 2004), ours defined target locations relative to a mobile reference point, and both studies observed allocentric-specific activation in ventrolateral occipital-temporal cortex. In natural circumstances, egocentric and allocentric cues are stable and agree with each other. Thus, they can be optimally integrated for reach (Byrne and Crawford, 2010), which likely involves cooperative network connections between the areas described in the current study. Finally, we used an explicit allocentric task; different cortical mechanisms may be involved in tasks where allocentric information is implicit (Byrne and Crawford, 2010).

\section{Parietofrontal direction selectivity in delay versus response phases}

We observed general activation of the parietofrontal reach network in the delay phase of both of our spatial tasks, presumably because our subjects were expecting to apply a rule-based visuomotor transformation upon the arrival of the subsequent gosignal for a reach movement (Hawkins et al., 2013). However, we were surprised that this activation was not directionally selective. This contradicts a study that reported ipsilateral direction preference in the monkey parietal reach region and PMd during a task very similar to our egocentric task (Westendorff et al., 2010), but those responses may have been biased by lengthy training on the anti-reach task. Conversely, the lack of parietofrontal direction selectivity in our delay phase data appears to contradict studies that showed contralateral directional selectivity in PPC during the delay between viewing a target and reaching toward it ( $\mathrm{Me}-$ dendorp et al., 2005a; Gail and Andersen, 2006). However, our subjects did not know what direction they would reach, relative to gaze/midline until the end of the delay phase. Thus, only target direction was coded in this phase, and our data suggest that this is not sufficient to evoke measureable parietofrontal direction selectivity in the human.

The latter conclusion suggests that additional motor signals are required to evoke parietofrontal direction selectivity. To test this, we analyzed egocentric directional selectivity during our response phase, after movement direction was specified. As predicted, directional selectivity reappeared through most of the expected components of the human parietofrontal reach network, including mIPS, SPL, AG, and PMd (Filimon, 2010; Vesia and Crawford, 2012). These data likely contained signals related to transformation of target memory into motor plans, commands, motor execution, and propriopceptive (but not visual) feedback. However, comparing the current data to studies where planning was separated from motor execution suggests that the conversion of target coding into planning, or planning itself, is sufficient to produce directional tuning in parietofrontal cortex (Medendorp et al., 2005a; Gail and Andersen, 2006).

These conclusions are harder to reconcile with studies that showed spatial selectivity in PPC in the absence of any overt movement (Duhamel et al., 1992; Colby et al., 1995; Merriam et al., 2003). It is possible that those subjects implicitly use motor imagery to help remember target location. Conversely, it is possible that, in our delay phase, parietofrontal target signals were masked by directionally nonspecific reach plans. Otherwise, our findings generally agree with the literature on movement planning in parietofrontal cortex (Kalaska and Crammond, 1992; Kalaska et al., 1997; Kakei et al., 2001; Andersen and Buneo, 2002; Beurze et al., 2009; Filimon et al., 2009).

\section{Asymmetry of cortical responses}

Overall, we found a greater propensity for left hemisphere activation (and concomitantly rightward target coding) in both the delay and response phases. This might be explained by inter- 
actions between hand laterization and visual hemifield lateralization (Perenin and Vighetto, 1988; Rossetti et al., 2003; Medendorp et al., 2005b; Beurze et al., 2007; Blangero et al., 2007; Vesia and Crawford, 2012). This has been shown before in parietal cortex (Fernandez-Ruiz et al., 2007) but is somewhat surprising that it also occurred in occipital cortex. Possibly this reflects feedback of reach signals to these areas. For example, even though subjects could not see their hand in our task, they may have visualized it (Filimon et al., 2007). It is also possible that this is related to attentional enhancement of visual stimuli near the hand (di Pellegrino and Frassinetti, 2000; Reed et al., 2006; Abrams et al., 2008). Together with our main result that occipital cortex encodes reach targets in both egocentric and allocentric coordinates, these results support the notion that occipital cortex plays a more important role in the guidance of action than often assumed (Pasternak and Greenlee, 2005).

\section{References}

Abrams RA, Davoli CC, Du F, Knapp WH 3rd, Paull D (2008) Altered vision near the hands. Cognition 107:1035-1047. CrossRef Medline

Andersen RA, Buneo CA (2002) Intentional maps in posterior parietal cortex. Annu Rev Neurosci 25:189-220. CrossRef Medline

Andersen RA, Snyder LH, Li CS, Stricanne B (1993) Coordinate transformations in the representation of spatial information. Curr Opin Neurobiol 3:171-176. CrossRef Medline

Andersen RA, Snyder LH, Batista AP, Buneo CA, Cohen YE (1998) Posterior parietal areas specialized for eye movements (LIP) and reach (PRR) using a common coordinate frame. Novartis Found Symp 218:109-122; discussion 122-128.

Astafiev SV, Shulman GL, Stanley CM, Snyder AZ, Van Essen DC, Corbetta M (2003) Functional organization of human intraparietal and frontal cortex for attending, looking, and pointing. J Neurosci 23:4689-4699. Medline

Batista AP, Buneo CA, Snyder LH, Andersen RA (1999) Reach plans in eyecentered coordinates. Science 285:257-260. CrossRef Medline

Beurze SM, de Lange FP, Toni I, Medendorp WP (2007) Integration of target and effector information in the human brain during reach planning. J Neurophysiol 97:188-199. CrossRef Medline

Beurze SM, de Lange FP, Toni I, Medendorp WP (2009) Spatial and effector processing in the human parietofrontal network for reaches and saccades. J Neurophysiol 101:3053-3062. CrossRef Medline

Beurze SM, Toni I, Pisella L, Medendorp WP (2010) Reference frames for reach planning in human parietofrontal cortex. J Neurophysiol 104: 1736-1745. CrossRef Medline

Blangero A, Ota H, Delporte L, Revol P, Vindras P, Rode G, Boisson D, Vighetto A, Rossetti Y, Pisella L (2007) Optic ataxia is not only 'optic': impaired spatial integration of proprioceptive information. Neuroimage 36 [Suppl 2]:T61-T68.

Bridgeman B, Peery S, Anand S (1997) Interaction of cognitive and sensorimotor maps of visual space. Percept Psychophys 59:456-469. CrossRef Medline

Brown MR, DeSouza JF, Goltz HC, Ford K, Menon RS, Goodale MA, Everling S (2004) Comparison of memory- and visually guided saccades using event-related fMRI. J Neurophysiol 91:873-889. Medline

Brown MR, Goltz HC, Vilis T, Ford KA, Everling S (2006) Inhibition and generation of saccades: rapid event-related fMRI of prosaccades, antisaccades, and nogo trials. Neuroimage 33:644-659. CrossRef Medline

Burnod Y, Baraduc P, Battaglia-Mayer A, Guigon E, Koechlin E, Ferraina S, Lacquaniti F, Caminiti R (1999) Parietofrontal coding of reaching: an integrated framework. Exp Brain Res 129:325-346. CrossRef Medline

Byrne PA, Crawford JD (2010) Cue reliability and a landmark stability heuristic determine relative weighting between egocentric and allocentric visual information in memory-guided reach. J Neurophysiol 103:30543069. CrossRef Medline

Byrne PA, Cappadocia DC, Crawford JD (2010) Interactions between gazecentered and allocentric representations of reach target location in the presence of spatial updating. Vision Res 50:2661-2670. CrossRef Medline

Carrozzo M, Stratta F, McIntyre J, Lacquaniti F (2002) Cognitive allocentric representations of visual space shape pointing errors. Exp Brain Res 147: 426-436. CrossRef Medline
Cavina-Pratesi C, Monaco S, Fattori P, Galletti C, McAdam TD, Quinlan DJ, Goodale MA, Culham JC (2010) Functional magnetic resonance imaging reveals the neural substrates of arm transport and grip formation in reach-to-grasp actions in humans. J Neurosci 30:10306-10323. CrossRef Medline

Chen Y, Byrne P, Crawford JD (2011) Time course of allocentric decay, egocentric decay, and allocentric-to-egocentric conversion in memoryguided reach. Neuropsychologia 49:49-60. CrossRef Medline

Colby CL, Duhamel JR, Goldberg ME (1995) Oculocentric spatial representation in parietal cortex. Cereb Cortex 5:470-481. CrossRef Medline

Committeri G, Galati G, Paradis AL, Pizzamiglio L, Berthoz A, LeBihan D (2004) Reference frames for spatial cognition: different brain areas are involved in viewer-, object-, and landmark-centered judgments about object location. J Cogn Neurosci 16:1517-1535. CrossRef Medline

Connolly JD, Goodale MA, DeSouza JF, Menon RS, Vilis T (2000) A comparison of frontoparietal fMRI activation during anti-saccades and antipointing. J Neurophysiol 84:1645-1655. Medline

Connolly JD, Andersen RA, Goodale MA (2003) FMRI evidence for a 'parietal reach region' in the human brain. Exp Brain Res 153:140-145. CrossRef Medline

Crawford JD, Henriques DY, Medendorp WP (2011) Three-dimensional transformations for goal-directed action. Annu Rev Neurosci 34:309331. CrossRef Medline

DeSouza JF, Dukelow SP, Gati JS, Menon RS, Andersen RA, Vilis T (2000) Eye position signal modulates a human parietal pointing region during memory-guided movements. J Neurosci 20:5835-5840. Medline

di Pellegrino G, Frassinetti F (2000) Direct evidence from parietal extinction of enhancement of visual attention near a visible hand. Curr Biol 10:1475-1477. CrossRef Medline

Duhamel JR, Colby CL, Goldberg ME (1992) The updating of the representation of visual space in parietal cortex by intended eye-movements. Science 255:90-92. CrossRef Medline

Fabbri S, Caramazza A, Lingnau A (2012) Distributed sensitivity for movement amplitude in directionally tuned neuronal populations. J Neurophysiol 107:1845-1856. CrossRef Medline

Fernandez-Ruiz J, Goltz HC, DeSouza JF, Vilis T, Crawford JD (2007) Human parietal "reach region" primarily encodes intrinsic visual direction, not extrinsic movement direction, in a visual motor dissociation task. Cereb Cortex 17:2283-2292. CrossRef Medline

Filimon F (2010) Human cortical control of hand movements: parietofrontal networks for reaching, grasping, and pointing. Neuroscientist 16:388 407. CrossRef Medline

Filimon F, Nelson JD, Hagler DJ, Sereno MI (2007) Human cortical representations for reaching: mirror neurons for execution, observation, and imagery. Neuroimage 37:1315-1328. CrossRef Medline

Filimon F, Nelson JD, Huang RS, Sereno MI (2009) Multiple parietal reach regions in humans: cortical representations for visual and proprioceptive feedback during on-line reaching. J Neurosci 29:2961-2971. CrossRef Medline

Fink GR, Marshall JC, Shah NJ, Weiss PH, Halligan PW, Grosse-Ruyken M, Ziemons K, Zilles K, Freund HJ (2000) Line bisection judgments implicate right parietal cortex and cerebellum as assessed by fMRI. Neurology 54:1324-1331. CrossRef Medline

Forman SD, Cohen JD, Fitzgerald M, Eddy WF, Mintun MA, Noll DC (1995) Improved assessment of significant activation in functional magnetic resonance imaging (fMRI): use of a cluster-size threshold. Magn Reson Med 33:636-647. CrossRef Medline

Gail A, Andersen RA (2006) Neural dynamics in monkey parietal reach region reflect context-specific sensorimotor transformations. J Neurosci 26:9376-9384. CrossRef Medline

Galati G, Lobel E, Vallar G, Berthoz A, Pizzamiglio L, Le Bihan D (2000) The neural basis of egocentric and allocentric coding of space in humans: a functional magnetic resonance study. Exp Brain Res 133:156-164. CrossRef Medline

Goodale MA, Haffenden A (1998) Frames of reference for perception and action in the human visual system. Neurosci Biobehav Rev 22:161-172. CrossRef Medline

Greenlee MW, Magnussen S, Reinvang I (2000) Brain regions involved in spatial frequency discrimination: evidence from fMRI. Exp Brain Res 132:399-403. CrossRef Medline

Harrison SA, Tong F (2009) Decoding reveals the contents of visual working memory in early visual areas. Nature 458:632-635. CrossRef Medline 
Hawkins KM, Sayegh P, Yan X, Crawford JD, Sergio LE (2013) Neural activity in superior parietal cortex during rule-based visual-motor transformations. J Cogn Neurosci 25:436-454. CrossRef Medline

Kakei S, Hoffman DS, Strick PL (2001) Direction of action is represented in the ventral premotor cortex. Nat Neurosci 4:1020-1025. CrossRef Medline

Kalaska JF, Crammond DJ (1992) Cerebral cortical mechanisms of reaching movements. Science 255:1517-1523. CrossRef Medline

Kalaska JF, Scott SH, Cisek P, Sergio LE (1997) Cortical control of reaching movements. Curr Opin Neurobiol 7:849-859. CrossRef Medline

Konen CS, Mruczek RE, Montoya JL, Kastner S (2013) Functional organization of human posterior parietal cortex: grasping- and reaching-related activations relative to topographically organized cortex. J Neurophysiol 109:2897-2908. CrossRef Medline

Krigolson O, Heath M (2004) Background visual cues and memory-guided reaching. Hum Mov Sci 23:861-877. CrossRef Medline

Krigolson O, Clark N, Heath M, Binsted G (2007) The proximity of visual landmarks impacts reaching performance. Spat Vis 20:317-336. CrossRef Medline

Medendorp WP, Goltz HC, Vilis T, Crawford JD (2003) Gaze-centered updating of visual space in human parietal cortex. J Neurosci 23:6209-6214. Medline

Medendorp WP, Goltz HC, Vilis T (2005a) Remapping the remembered target location for anti-saccades in human posterior parietal cortex. J Neurophysiol 94:734-740. CrossRef Medline

Medendorp WP, Goltz HC, Crawford JD, Vilis T (2005b) Integration of target and effector information in human posterior parietal cortex for the planning of action. J Neurophysiol 93:954-962. CrossRef Medline

Merriam EP, Genovese CR, Colby CL (2003) Spatial updating in human parietal cortex. Neuron 39:361-373. CrossRef Medline

Merriam EP, Genovese CR, Colby CL (2007) Remapping in human visual cortex. J Neurophysiol 97:1738-1755. Medline

Milner AD, Goodale MA (1995) The visual brain in action. Oxford: Oxford UP.

Milner AD, Goodale MA (2006) The visual brain in action. Oxford: Oxford UP.

Milner AD, Goodale MA (2008) Two visual systems re-viewed. Neuropsychologia 46:774-785. CrossRef Medline

Neggers SF, Van der Lubbe RH, Ramsey NF, Postma A (2006) Interactions between ego- and allocentric neuronal representations of space. Neuroimage 31:320-331. CrossRef Medline

Obhi SS, Goodale MA (2005) The effects of landmarks on the performance of delayed and real-time pointing movements. Exp Brain Res 167:335344. CrossRef Medline

Olson CR (2003) Brain representation of object-centered space in monkeys and humans. Annu Rev Neurosci 26:331-354. CrossRef Medline

Olson CR, Gettner SN (1995) Object-centered direction selectivity in the macaque supplementary eye field. Science 269:985-988. CrossRef Medline

Olson CR, Tremblay L (2000) Macaque supplementary eye field neurons encode object-centered locations relative to both continuous and discontinuous objects. J Neurophysiol 83:2392-2411. Medline

Pasternak T, Greenlee MW (2005) Working memory in primate sensory systems. Nat Rev Neurosci 6:97-107. CrossRef Medline

Perenin MT, Vighetto A (1988) Optic ataxia: a specific disruption in visuomotor mechanisms: I. Different aspects of the deficit in reaching for objects. Brain 111:643-674. CrossRef Medline

Prado J, Clavagnier S, Otzenberger H, Scheiber C, Kennedy H, Perenin MT (2005) Two cortical systems for reaching in central and peripheral vision. Neuron 48:849-858. CrossRef Medline

Reed CL, Grubb JD, Steele C (2006) Hands up: attentional prioritization of space near the hand. J Exp Psychol Hum Percept Perform 32:166-177. CrossRef Medline

Rossetti Y, Pisella L, Vighetto A (2003) Optic ataxia revisited: visually guided action versus immediate visuomotor control. Exp Brain Res 153: 171-179. CrossRef Medline

Sabes PN, Breznen B, Andersen RA (2002) Parietal representation of objectbased saccades. J Neurophysiol 88:1815-1829. Medline

Schenk T (2006) An allocentric rather than perceptual deficit in patient D.F. Nat Neurosci 9:1369-1370. CrossRef Medline

Schütz I, Henriques DY, Fiehler K (2013) Gaze-centered spatial updating in delayed reaching even in the presence of landmarks. Vision Res 87:46-52. CrossRef Medline

Thaler L, Goodale MA (2011) Neural substrates of visual spatial coding and visual feedback control for hand movements in allocentric and targetdirected tasks. Front Hum Neurosci 5:92. CrossRef Medline

Vesia M, Crawford JD (2012) Specialization of reach function in human posterior parietal cortex. Exp Brain Res 221:1-18. CrossRef Medline

Westendorff S, Klaes C, Gail A (2010) The cortical timeline for deciding on reach motor goals. J Neurosci 30:5426-5436. CrossRef Medline

Zaehle T, Jordan K, Wüstenberg T, Baudewig J, Dechent P, Mast FW (2007) The neural basis of the egocentric and allocentric spatial frame of reference. Brain Res 1137:92-103. CrossRef Medline 